\title{
Central Clinical Trial Filenote
}

National Cancer Institute

\section{Source}

National Cancer Institute. Central Clinical Trial Filenote. NCI Thesaurus. Code C115546.

A notation that describes the decisions, and/or clarification of any information pertaining to the central trial. 